\title{
A panacéia tecnológica e a perspectiva do valor de uso
}

\author{
Mauro Castelo Branco de Moura ${ }^{1}$
}

A modernidade, sobretudo em seu apogeu iluminista, ensejou a crença num devir auspicioso fundado, segundo Adam Smith, no desenvolvimento das forças produtivas do trabalho [productive powers of labour]. Porém, ainda no século XVIII, em meio a um otimismo generalizado, que se consagrou com a gênese da historicidade (entendida como "progresso") e espraiou-se através de autores como Kant ou Condorcet, já se insurgia Rousseau contra a crença da técnica como panacéia para a resolução dos problemas humanos. À esteira de ambos (Smith e Rousseau), Marx demonstra que o capital é um poderoso estimulante ao desenvolvimento das forças produtivas, mas traz aparelhado em si a submissão estranhada do processo de reprodução social à valorização do valor [Verwertungs des Werts], com o quinhão de barbárie que lhe é inerente. O crescimento permanente e ilimitado da riqueza abstrata que carateriza o capital, figura apoteótica da tríade fetichóide (mercadoria, dinheiro e capital), só se pode consumar às expensas da subordinação da satisfação das necessidades (e da vida) humanas a seu desiderato, pela imposição de seu automatismo, que subalterniza todas as apetências.

Se as mercadorias profanas [profane Waren] necessitam de guardiães que as levem ao mercado, o capital configura energúmenos, que são apoderados pela "lógica" do processo de valorização e limitam-se a balbuciar um discurso reiterativo de

$---{ }_{-1}^{-}-$

1 Professor Doutor do Departamento de Filosofia da Universidade Federal da Bahia - UFBA.

cadernos cemarx, $n ^ { 0 } 2 - 2 0 0 5 \longdiv { 5 9 }$ 
conformidade aos seus (do capital) desígnios. Por esta razão, pôde Marx afirmar, sem rodeios, que:

A circulação simples de mercadorias - a venda para compra - serve de meio para um objetivo final que está fora da circulação, a apropriação de valores de uso, a satisfação de necessidades. A circulação do dinheiro como capital é, pelo contrário, uma finalidade em si mesma, pois a valorização do valor só existe dentro deste movimento sempre renovado. Por isso o movimento do capital é insaciável. Como portador consciente desse movimento, o possuidor do dinheiro torna-se capitalista. Sua pessoa, ou melhor, seu bolso, é o ponto de partida e o ponto de retorno do dinheiro. O conteúdo objetivo daquela circulação - a valorização do valor - é sua meta subjetiva, e só enquanto a apropriação crescente da riqueza abstrata é o único motivo indutor de suas operações, ele funciona como capitalista ou capital personificado, dotado de vontade e consciência² .

Destarte é a perspectiva do valor de uso que permite a Marx iluminar o capitalismo, denunciando-o. Daí seu freqüente recurso e encômio à obra de Aristóteles.

Com efeito, a forma mercadoria configura-se por uma tensão constitutiva que se desdobra em seus dois atributos: o valor de uso e o valor. À utilidade (valor de uso) subjetivamente fundada em qualidades diferenciadas e sensorialmente perceptíveis (enquanto se destina à satisfação de apetências) - contrapõe-se o valor - propriedade social objetiva e homogênea (enquanto puramente quantitativa e extra-sensorial) - que se origina do confronto no mercado, sob as formas relativa e equivalencial, dos produtos do trabalho privado. Ao primeiro atributo, que transcende à socialidade burguesa $e$ não oferece maiores obstáculos à intelecção, acopla-se o outro, cujo caráter peculiar obnubila-lhe o sentido, convertendo-o em um verdadeiro hieróglifo social a ser devidamente decifrado: trata-se do fenômeno descrito por Marx como fetichismo mercantil.

Se em sua forma mais prosaica (na mercadoria), configurada por uma faceta absolutamente diáfana (o valor de uso), o valor já resplandece como um absconso enigma, em seus desdobramentos subseqüentes o mistério só se incrementa. A forma dinheiro emerge para Marx como um resultado necessário da hipóstase transfigura-

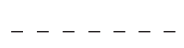

2 Karl Marx, 0 Capital, Livro I, Vol. 1, São Paulo, Nova Cultural, 1985, p. 129 [Das Kapital, I, MEW, Tomo 23, Berlim, Dietz, 1972, p. 166-167].

60 A panacéia tecnológica e a perspectiva do valor de uso 
da do valor com a disseminação do intercâmbio mercantil e é por ele definido como "a figura consumada do equivalente geral" [der fertingen Gestalt des allgemeinen Äquivalents]. "O dinheiro, como a riqueza puramente abstrata, na que se extingue todo valor de uso específico [...]"3 porque sua única utilidade, enquanto tal, consiste em expressar (ou refletir) a forma relativa de valor das diferentes mercadorias, pode, inclusive, desmaterializar-se, incorporando assim sua fantasmagoria plena. Por isso Marx pôde afirmar que "o enigma do fetiche do dinheiro é, portanto, apenas o enigma do fetiche da mercadoria, tornado visível e ofuscante" ${ }^{\prime 4}$. Às simples mercadorias denominou-as profanas [profane Waren] e ao dinheiro, à esteira de Shakespeare, divindade visivel [sichtbare Gottheit] ${ }^{5}$.

Sem embargo, o objeto de sua obra magna, como seu próprio título indica, é o capital. A baldeação pelas formas mercadoria e dinheiro foi o recurso imprescindível para que pudesse chegar à sua tematização. Para a economia política o capital sempre foi um fato empírico inquestionável, porém, para Marx, não pode ser aceito sem um exame prévio. Associa-se ele, portanto, à milenar tradição filosófica que se dedica ao exame de supostas evidências... Para chegar à forma capital teve que escrutar cuidadosamente a mercadoria e o dinheiro, uma vez que ela (a forma capital) pode ser descrita, em sua fórmula mais concisa, como D-M-D' (dinheiro-mercadoria-dinheiro incrementado), onde $\mathrm{D}^{\prime}=\mathrm{D}+\mathrm{A} \mathrm{D}$. Trata-se, por esta razão, de uma figura processual, que se funda na metamorfose entre dinheiro e mercadoria, porém com um rédito: o ÄD. Marx dedica as duas primeiras seções do Livro I d'O Capital a enunciar (e denunciar) o enigma do ÄD, leitmotiv do capital. Vale dizer, ele problematiza aquilo que a economia política aceita, sem questionamentos, como empiricamente evidente.

Não obstante, o caráter absconso do valor, em suas sucessivas hipóstases, só pode ser iluminado a partir do valor de uso, atributo constitutivo da figura mais singela (a mercadoria), porém que se esfuma em seu desdobramento subseqüente (dinheiro) e está alheio ao leitmotiv da figura processual, cujo telos imanente está na riqueza abstrata e não na concreta. Por esta razão Marx pôde afirmar que

[...] o capital a juros constitui o fetiche mais completo. Encontramos

$$
---\cdot-
$$

3 Karl Marx, Lineamientos Fundamentales de la Crítica de la Economía Política [Grundrisse], 2 Tomos, México, Fondo de Cultura Económica, 1985, Tomo II, p. 413.

4 Karl Marx, 0 Capital, cit., p. 85 [Das Kapital, p. 108].

5 Cf. Karl Marx, “Nationalökonomie und Philosophie (1844)”, in Die Frühschriften, Stuttgart, Alfred Kröner, 1959, p. 299.

cadernos cemarx, $n^{0} 2-2005 \mid 61$ 
aqui o primeiro ponto de partida do capital - o dinheiro - e a fórmula D-MD', reduzida aos seus dois extremos D-D'. Dinheiro que cria mais dinheiro. É a fórmula mais originária e geral do capital concentrada num resumo sem sentido ${ }^{6}$.

E este nonsense, é claro, só pode ser vislumbrado desde a perspectiva do valor de uso, que, ademais, é a da vida humana em sua finitude, já que o valor é, per se, enquanto domínio da riqueza abstrata, ilimitado.

David Ricardo, no início de seus Principles, afirmava que "Possuindo utilidade, as mercadorias derivam seu valor de troca de duas fontes: de sua escassez e da quantidade de trabalho necessária para obtê-las" ". Seria absurdo produzir algo que a natureza ofereça imediata e espontaneamente em abundância. Alfred Marshall denomina "bens livres" àqueles valores de uso que, independentemente de sua imprescindibilidade, como a do ar, por exemplo, nem podem ser alvos da apropriação privada. Destarte, se a escassez é um dos pilares do valor, a abundância é a condição para sua abolição e é nela, portanto, que o comunismo, para Marx, deve se fundar. E aqui é importante esclarecer um recorrente mal-entendido.

O dogma da propensão ilimitada ao consumo, que povoa certos manuais de economia, apenas traveste o postulado metafísico moderno, onde a vontade e a liberdade agigantam-se de tal maneira que não conhecem limites, fundamentando, para Descartes, a própria imagem e semelhança com Deus ${ }^{8}$. Estas características do individualismo burguês e de seu egoísmo constitutivo, transformam-se para Hobbes nas premissas de um conflito generalizado prévio à configuração da sociedade civil, inerente à própria condição humana; pois, antes dos pactos, "[...] era lícito a cada qual fazer o que the aprouvesse diante de quem-quer-que-seja, e apoderarse, para usar e desfrutar, de tudo que quisesse e pudesse"". Esta cupidez genésica, fundamento da guerra de todos contra todos, pode ser interpretada como o modo hobbesiano de enxergar a etiologia do confronto entre proprietários privados independentes no mercado.

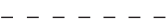

6 Karl Marx, “O Rendimento e suas Fontes", In: Karl Marx, São Paulo, Abril Cultural, Col. Os Economistas, 1982, p. 189. 7 David Ricardo, Princípios de Economia e Tributação, São Paulo, Abril Cultural, Col. Os Economistas, 1982, p. 43. 8 Cf. René Descartes, Meditationes de Prima Philosophia, Campinas, IFCH/UNICAMP, Ed. Bilíngüe, 1994, Meditatio Quarta, 59, p. 16.

9 Thomas Hobbes, De Cive, Petrópolis, Vozes, 1993, p. 54.

62 A panacéia tecnológica e a perspectiva do valor de uso 
No plano ordinário da vida humana, no entanto, em sua mesquinha finitude, esta volição desmesurada não pode encontrar guarida, posto que, no âmbito da riqueza concreta, se do ponto de vista da qualidade a satisfação das necessidades não configura, em princípio, limites, sendo seus contornos abertos; sob o prisma da quantidade, a delimitação parece evidente. O valor de uso das mercadorias só pode ser efetivamente desfrutado pelos indivíduos humanos em quantidades limitadas; apenas o consumo produtivo tende à ilimitação, enquanto substrato do processo de valorização, que caracteriza o capital, responsável pelo produtivismo desmedido. Reduzidas a simples objetos práticos, as mercadorias esbarram nos limites quantitativos das apetências humanas. Não se pode comer, beber, vestir, morar, transportar, etc., em quantidades ilimitadas. Pelo contrário, há limites físicos à capacidade individual (e, no somatório, à coletiva) de consumo.

Só a riqueza abstrata, qual o próprio Deus, pode não ter limites. Sua desmesura constitutiva ofusca o verdadeiro caráter da riqueza concreta, permitindo que se lhe impute à última atributos que não possui, condenando os incautos à indistinção entre as riquezas concreta e abstrata, algo que o pensamento peripatético já ensinara de há muito como fazer. "Tomemos, por exemplo, um sapato [propôs Aristóteles]: existe seu uso como sapato e existe seu uso como artigo de intercâmbio"10. Destarte, a perspectiva do valor de uso é aquela que permite circunscrever o âmbito da riqueza abstrata. Confrontado com a perenidade da utilidade, condição de possibilidade da vida humana, em qualquer momento histórico, o valor revela-se apenas um atributo transitório, histórico, confinado à formas da socialidade mercantil. Conferir-lhe a abrangência do valor de uso é apenas mais um mito burguês...

Conviria, portanto, com respeito à tecnologia, desembaraçar, ao menos teoricamente, a produção da riqueza concreta de sua submissão ao processo de valorização. A constatação de que o capital promove uma incessante revolução das forças produtivas, em virtude da permanente alteração de sua composição orgânica, com um peso crescente do "trabalho morto" em relação ao "vivo", explica seu profundo interesse pelos resultados da ciência, porém, não a converte num atributo do capital. Inclusive porque ele também tolhe os movimentos da ciência, submetendo-a a seu ritmo e interesses, para não falar da dilapidação dos recursos

10 Aristóteles, “Política", In: Obras, Madri, Aguilar, 1973, p.1420 [1257a].

cadernos cemarx, $\mathrm{n}^{0} 2-2005 \mid \mathbf{6 3}$ 
naturais e da destruição periódica das forças produtivas que auspicia, através de sucessivas crises cíclicas. Não se pode sorrateiramente escamotear a fonte permanente de disseminação de barbárie que se esconde sob o manto do culto da riqueza abstrata, posto que, se a produção da riqueza concreta não é, per se, descontrolada, a valorização do valor sim...

64 A panacéia tecnológica e a perspectiva do valor de uso 